\title{
Research
}

\section{Relocating patients from a specialist homeless healthcare centre to general practices:}

\author{
a multi-perspective study
}

\begin{abstract}
\section{Background}

The relocation of formerly homeless patients eligible to transfer from a specialist homeless healthcare centre (SHHC) to mainstream general practices is key to patient integration in the local community. Failure to transition patients conferring eligibility for relocation may also negatively impact on SHHC service delivery.
\end{abstract}

\section{Aim}

To explore barriers and facilitators of relocation from the perspectives of formerly homeless patients and healthcare staff involved in their care.

\section{Design and setting}

Qualitative semi-structured face-to-face and telephone interviews conducted in the north east of Scotland.

\section{Method}

Participants were patients and healthcare staff including GPs, nurses, substance misuse workers, administrative, and local community pharmacy staff recruited from one SHHC, two mainstream general practices, and four community pharmacies. Interview schedules based on the 14 domains of the Theoretical Domains Framework (TDF) were drafted. Transcripts of the interviews were analysed by two independent researchers using a framework approach.

\section{Results}

Seventeen patients and 19 staff participated. Key barriers and facilitators aligned to TDF domains included: beliefs about consequences regarding relocation; patient intention to relocate; environmental context and resources in relation to the care of the patients and assessing patient eligibility; patient skills in relation to integration: social and professional role and identity of staff and patients; and emotional attachment to the SHHC.

\section{Conclusion}

Implementation of services, which promote relocation and integration, may optimise patient relocation from SHHCs to mainstream general practices. These include peer support networks for patients, better information provision on the relocation process, and supporting patients in the journey of identifying and adjusting to mainstream practices.

\section{Keywords}

delivery of health care; general practice; homeless persons; primary health care; Theoretical Domains Framework.

\section{INTRODUCTION}

Homelessness embodies many forms, including rough sleeping, living in derelict buildings, temporary shelters, squats, or sofa surfing. ${ }^{1}$ Homelessness is a widespread issue in the UK. ${ }^{2}$ An estimated 250000 people are known to be currently homeless in England alone. ${ }^{3}$ More than 88000 households in England submitted a homeless application in 2016-2017, ${ }^{4}$ while in Scotland, the figure in $2015-2016^{5}$ was 34000 households. Evidence suggests that homeless individuals are significantly disadvantaged in terms of attaining health services and maintaining healthy lifestyles..$^{6-9}$ For example, individuals facing homelessness often experience difficulty in registering at mainstream general practices because of issues such as being unable to provide evidence of a permanent address $^{10,11}$ or photographic identification. ${ }^{12}$ Consequences include homeless patients attending accident and emergency departments to access health care or failing to access any healthcare services. ${ }^{11,13}$

There has been an emergence across the UK of specialist homeless general practices and general practices with particular expertise in homelessness. ${ }^{10,11}$ To the authors' knowledge there is at least one

K Gibson Smith, PhD, research fellow;

K MacLure, PhD, senior research fellow and

lecturer; D Stewart, PhD, professor of pharmacy practice, School of Pharmacy and Life Sciences: K Forbes-McKay, PhD, lecturer in social studies, School of Applied Social Studies, Rober Gordon University, Aberdeen. V Paudyal, PhD senior lecturer in pharmacy practice, School of Pharmacy, Institute of Clinical Sciences, University of Birmingham, Birmingham. C Buchanan MRCGP; GP; L Wilson, RNP, nurse practitioner, Marywell Healthcare Centre, NHS Grampian, Aberdeen. J MacLeod, MRPharmS, community health partnership pharmacist; A Smith, MRPharmS, Community Health Partnership Pharmacist, Aberdeen City Health \& Social Care Partnership, Aberdeen. such specialist homeless healthcare centre (SHHC) in every major city in the $\mathrm{UK}$, including several in Greater London, which mainly offer primary general practice services. Some of these centres constitute a registration list size of more than 1000 homeless people (Health Xchange Birmingham, personal communication, 2017). The establishment of these SHHCs has been led mainly by the specialist healthcare need of this population, as well as the preference of the homeless population to have dedicated drop-in centres instead of facilitated access to mainstream general practices. ${ }^{14}$

The value of such specialist services has been highlighted in terms of overcoming barriers associated with registration at a mainstream practice, ${ }^{15,16}$ and providing specialist care, such as substance misuse services, to the specific needs of homeless populations. ${ }^{17}$ Nevertheless, it has been suggested that transferring registration to a mainstream practice, once the patient has been stabilised, is an important aspect of improving recovery. ${ }^{18}$ This would facilitate appropriate use of finite specialist resources, reduce health inequalities, and support patient integration in the local community. There is a cognisance that relocation is not straightforward and there are barriers

\section{Address for correspondence}

Vibhu Paudyal, School of Pharmacy, College of Medical and Dental Sciences, Sir Robert Aitken Institute for Medical Research, University of Birmingham, Edgbaston, Birmingham B15 2TT, UK.

Email: v.paudyalabham.ac.uk

Submitted: 15 February 2017; Editor's response: 6 June 2017; final acceptance: 18 July 2017. cBritish Journal of General Practice This is the full-length article (published online 16 Jan 2018) of an abridged version published in print. Cite this version as: Br J Gen Pract 2018; DOI: https://doi.org/10.3399/bjgp18X694577 


\section{How this fits in}

The value of specialist homeless healthcare centres (SHHCs) has been highlighted in terms of overcoming the barriers associated with registration at a mainstream general practice and in the provision of specialised services that meet the distinct needs of the homeless population. Relocation to a local mainstream general practice is encouraged once patients are clinically stabilised and permanently housed, however, there may be numerous barriers that are difficult to overcome. This research sought to identify the key barriers and facilitators of relocation from a SHHC to a mainstream general practice. The findings highlight how relocation may be supported further within the patient group and support a series of recommendations.

that may be difficult for people who were formerly homeless to overcome. 19,20

This study aimed to explore the barriers and facilitators of relocating patients from a SHHC to mainstream general practice

\section{Box 1. Theoretical Domains Framework domains ${ }^{21}$}

\section{Beliefs about capabilities}

- Acceptance of the truth, reality, or validity about an ability, talent, or facility that a person can put to constructive use

\section{Beliefs about consequences}

- Acceptance of the truth, reality, or validity about outcomes of a behaviour in a given situation Behavioural regulation

- Anything aimed at managing or changing objectively observed or measured actions

Goals

- Mental representations of outcomes or end states that an individual wants to achieve

Emotions

- A complex reaction pattern, involving experiential, behavioural, and physiological elements, by which the individual attempts to deal with a personally significant matter or event

\section{Environmental context and resources}

- Any circumstance of a person's situation or environment that discourages or encourages the development of skills and abilities, independence, social competence, and adaptive behaviour

Intentions

- A conscious decision to perform a behaviour or a resolve to act in a certain way

Knowledge

- An awareness of the existence of something

Memory, attention, and decision processes

- The ability to retain information, focus selectively on aspects of the environment, and choose between two or more alternatives

Optimism

- The confidence that things will happen for the best or that desired goals will be attained

Reinforcement

- Increasing the probability of a response by arranging a dependent relationship, or contingency, between

the response and a given stimulus

Skills

- An ability or proficiency acquired through practice

\section{Social influences}

- Those interpersonal processes that can cause individuals to change their thoughts, feelings, or behaviours Social and professional role and identity

- A coherent set of behaviours and displayed personal qualities of an individual in a social or work setting from the perspectives of formerly homeless patients and staff involved in their care. The Theoretical Domains Framework (TDF), which may be adopted as a framework in both implementation and behaviour change research, was used to elucidate the barriers and facilitators of patients relocation. The TDF outlines 14 domains of behavioural determinants (Box 1), each embodying individual constructs, and which represents a synthesis of 33 behaviour change theories. The framework may be used as a means to inform the development of behaviour change interventions. ${ }^{21}$ In this study, the framework enabled theoretical characterisation of likely factors that may impact on patients' relocation behaviour from the perspective of formerly homeless patients and staff involved in their care.

\section{METHOD}

The study used a qualitative methodology to collect rich data on the barriers and facilitators of relocation. The study was conducted in the north east of Scotland from February to October 2016 in a SHHC that has been operating since 2006.22 The practice had a patient population of approximately 400, most of whom were homeless, and male, aged 25-44 years old with approximately $50 \%$ being prescribed methadone.

Qualitative in-depth interviews were conducted with patients at the SHHC Iwho were eligible to relocate based on health and accommodation) and those who had relocated recently from the specialist centre to a general practice in the locality of their permanent address. Patients deemed eligible for relocation were provided with details of the study when they presented for appointments at the SHHC. Those expressing interest were directed to the researcher, who was present on site, and was able to provide further information and answer any questions before inviting consent. All patients who consented to participate were interviewed. GPs, nurses, and administrative staff from the $\mathrm{SHHC}$ and mainstream general practices, in addition to staff from community pharmacies involved in the care of homeless patients, were also invited to take part and those who consented were interviewed. Mainstream general practices that were invited to take part in the research were selected based on the knowledge that a significant proportion of patients from the SHHC had been relocated to these practices. Pharmacies were identified and selected by the community health partnership pharmacist based on the extent of service provision 


\section{Table 1. Demographics of patient participants $(n=17)^{\mathrm{a}}$}

\begin{tabular}{llc} 
Demographic & Category & $\boldsymbol{n}$ \\
\hline Recruitment site & SHHC & 12 \\
& Mainstream practice & 5 \\
\hline Sex & Female & 3 \\
& Male & 10 \\
\hline Length of time homeless & $<6$ months & 3 \\
& 6 months to 1 year & 0 \\
\hline Self-reported general health & 3-2 years & 5 \\
& $\geq 5$ years & 2 \\
& Very good & 3 \\
\hline & Good & 1 \\
& Fair & 0 \\
\hline
\end{tabular}

a Please note demographic data were not available for some participants because of patient reluctance to provide such data and inadvertent omission. SHHC = specialist homeless healthcare centre

to the currently and formerly homeless population

The interview schedules were informed by the TDF and drafted by the research team. Separate interview schedules lavailable from the authors on request) for each stage of the research were reviewed by researchers with expertise in health services research and health psychology for credibility. This was followed by piloting with two staff members and two patients and, as piloting resulted in minimal changes to the interview schedules, their responses were included in the study dataset.

Informed written consent and demographic data were obtained before conducting interviews. Semi-structured interviews were conducted by experienced qualitative researchers, either face-toface or by telephone, depending on each

Table 2. Demographics of staff participants $(n=19)$

\begin{tabular}{lll} 
Demographic & Category & $\boldsymbol{n}$ \\
\hline Recruitment site & SHHC & 7 \\
& Mainstream practice & 8 \\
\hline Sexa & Pharmacy & 4 \\
\hline Job title & Female & 15 \\
& Male & 3 \\
\hline & GP & 4 \\
\hline Please note demographic data (sex) were not collected for one participant. SHHC = specialist homeless healthcare & 4 \\
centre. & Purse & 4 \\
& Sharmacist & 5 \\
\end{tabular}

participant's preference. Interviews were audiorecorded, with permission, and transcribed verbatim. Each transcript was analysed independently by two researchers using a framework approach. ${ }^{23}$ The analytical method involves multiple stages of familiarisation with the interview; coding; developing an analytical framework; applying the analytical framework; and charting and interpreting data. ${ }^{24}$ The TDF was applied deductively to the data and used to inform the analytical framework. Transcription and analysis was ongoing throughout data collection. Saturation of data was assumed after no new themes emerged. ${ }^{25}$

\section{RESULTS}

\section{Demographics}

Patients $(n=17)$ were aged $30-48$ years ( mean $=40.3$, standard deviation $=5.4$ ) and most were male, had experienced homelessness for more than 1 year, and described their general health as 'fair' (Table 1). Nineteen staff participants were recruited. They were aged 27-65 years old, with most being female administrative members of staff (Table 2). Qualitative findings are presented in relation to themes within the 10 TDF domains identified in the analysis. Four TDF domains were not identified in the analysis: goals; behavioural regulation; optimism; and memory, attention, and decision processes.

\section{Beliefs about consequences}

Staff lin an effort to maintain anonymity staff regardless of profession are hereby referred to as staff after quotations) and patients described several consequences of relocation, which they perceived as barriers. Themes were identified relating to patient concern over continuation of their ongoing healthcare needs on relocation; apprehension about meeting new staff at mainstream practices; ability to integrate; and perceptions of mainstream practice.

For example, one patient noted their concern regarding the establishment of new relationships at mainstream practices and potential stigma:

'Obviously, you've got a little concern that you're going to get on with your doctor and you're going to like your doctor and they're going to, like, take to you and not look their nose down to you because of your past and stuff.' (Patient 1, female, age 40 years, mainstream practice)

This was further emphasised by a staff participant: 
A lot of them feel if they go to a mainstream surgery they're classed as a, they're treated as a second class citizen.' (Staff 9. pharmacyl

\section{Intentions}

Patient intentions were described by staff and patients as key to relocation. Themes included intentions to relocate and reluctance to relocate. While some patients initiated the relocation process themselves, others expressed a reluctance to relocate. Factors affecting intentions included ongoing treatment and the negative experiences of others who had previously moved.

As noted by one staff participant, some patients were reluctant to relocate:

A number of people who I suppose l've worked with over a period of time would probably rather just stay there because they know it and it's, you know, the people and it is probably a hassle to have to go and find a GP practice and go along and fill in forms and do it all.' (Staff 7, mainstream practice)

One patient stated that they felt that they would not move because of the experience of others:

In my personal opinion I wouldn't move after what l've seen over the last 6 months of somebody moving from here to somewhere else. It's just an absolute joke and / just [feel] that [is] pathetic.' (Patient 7. no demographic data available, SHHC)

\section{Environmental context and resources}

Staff and patients discussed the impact of environmental context and resources on relocation and integration. Key themes included lack of effective means to establish a patient's housing status lalthough patient eligibility for relocation was also considered in terms of clinical stability); SHHC resources in communicating and assisting people to relocate; communication between $\mathrm{SHHC}$ and mainstream practice; diverse policies and operating rules in mainstream practices in registering patients such as photographic identification requirements; a patient's access to resources, for example a telephone; and a lack of continuity of services such as podiatry and dentistry at mainstream practices after relocation.

A staff participant at the SHHC explained how continuity of services to mainstream practices could prove problematic:

'Other care, dental services here, no longer homeless they wouldn't be able to access that, they would need to go and register elsewhere. Podiatry services that we've got here they wouldn't, they just would be unlikely to access that cause the services are not available for straightforward foot care.' (Staff 5, SHHC)

Further, one patient, described how the SHHC offered a level of specialised care which was unparalleled:

Just the underlying issues that I have at the moment that I don't feel they can facilitate the best way as what this practice [SHHC] can, for me, at the moment.' (Patient 12. female, age 30 years, $\mathrm{SHHC}$ )

\section{Knowledge}

Themes identified by staff and patients included patients' knowledge of administrative processes involved in relocation; an awareness of eligibility for relocation; knowledge of mainstream practices in their local area; and a lack of knowledge of the rules and policies of mainstream practices, as well as knowledge and experience of SHHC staff in managing homeless and formerly homeless patients.

One staff participant underscored how it may be beneficial for patients relocating to be made aware of the regulations and policies of mainstream practices:

I think they need to have a bit of learning before they leave SHC to say that, I mean, I've worked at SHC so I understand that, I know what happens with them, they don't turn up for their appointment in the morning but they get their script in the afternoon, there's not a GP there. It's, appears quite easy to do that but they have to understand when they're at a practice like us we're nae going to do that.' (Staff 1, mainstream practice)

\section{Skills}

The importance of patient skills was identified in relation to a theme regarding integrating and adapting to the culture of mainstream practices. One patient experienced little difficulty in integrating:

'Yeah, I've just been twice since I moved and everything's been okay, transferred nae problem at all.' (Patient 3, male, mainstream practice)

However, it was suggested that some patients may experience issues integrating into mainstream practices:

We do find them [relocated patients] challenging people to, to try and integrate into our way of working, shall we say. '(Staff 


\section{2, mainstream practice)}

\section{Social and professional role and identity}

Both patients and staff identified the influence of social and professional roles and identities in relocation.

Themes included patients self-identifying as homeless and expectation of negative perceptions; patients not perceiving the SHHC as a specialist practice for those experiencing homelessness; changing healthcare/lifestyle needs of patients serving as a prompt to relocation; the role of staff at the $\mathrm{SHHC}$ in facilitating relocation; and the ability of pharmacy staff to assist in the relocation process.

One pharmacist described their potential role in the relocation process:

Because we see these patients everyday we're obviously in a very good position to be able to speak to them, we've got good relationships with them so we could use those relationships to be able to support them and find out more information about their movement from one practice to another.' (Staff 1, pharmacy)

From a patient's perspective, staff at the $\mathrm{SHHC}$ can have a positive role in facilitating relocation:

She [staff member at SHHC] would always be like "have you found another practice? If you need any help, if you go up and they're like, we're not taking anybody else', phone me and I'll speak to them if you want". (Patient 3, male, mainstream practice)

\section{Beliefs about capabilities}

Staff and patients described a key theme relating to self and patient's perceived ability to integrate into mainstream practice. Selfesteem and confidence were regarded as critical concepts impacting a person's ability to integrate. A staff participant discussed the ability of patients to integrate particularly in terms of building confidence:

I think the self-esteem and the confidence and, you know, kind of that element of it takes so much longer to build back up in the person.' (Staff 1, SHHC)

\section{Social influences}

Both staff and patients identified the impact of social influences on relocation. The principal themes identified illustrated the influence of health and social care professionals, administrative staff, and family and friends in promoting relocation, and the experiences and influences of patients who had relocated previously.

For example, the experiences of others who had previously relocated both positively and negatively influenced an individual's willingness to relocate and the practice that was selected for relocation:

'[Patient's] been cut off heaps of stuff [services post-relocation] in the space of 6 month and just completely a joke ... so, in my point of view, moving practice, just with personal experience with somebody that I ken I just, I wouldn't be happy about moving set up like.' (Patient 6, male, age 34 years, $\mathrm{SHHCl}$

This theme was further emphasised by a staff participant:

Maybe they hae friends that are here [mainstream practice] and thinking "well, I'll just, I'll just go".' (Staff 1, mainstream practice]

\section{Reinforcement}

Reinforcement was discussed by staff and one patient primarily in the context of healthcare professionals, administrative staff, social care workers, and family and friends who were perceived as important in facilitating and reinforcing relocation.

It was highlighted that staff often discussed the benefits of relocation, such as a greater availability of appointments at mainstream practices, in an effort to incentivise and motivate eligible patients:

We always try to portray the positive, you know, "this is you moving on, the range of services, the timescales, you know GPs to choose from, you choose your own GP, you could get a late appointment after your work or before you work". '(Staff 4, SHHC)

One patient explained how patients were unlikely to relocate unless staff at the SHHC reinforced it:

No, just, just, the only way people are going to move is if somebody sits down and does it for them, and that's real, that's realistically the truth isn't it?' (Patient 1, female, age 40 years, mainstream practice)

\section{Emotion}

Emotion was identified by staff and patients as influential in the decision to relocate. Themes identified were patient expression of emotions in relation to relocation and emotional attachment to the SHHC.

For example, an individual's emotional 
attachment to the SHHC often presented as a barrier to relocation. This was mentioned by staff:

I guess the fact that if you had been seeing one doctor for a long time and then all of a sudden you need to go to somewhere different everyone would kind of feel that initial anxiety but I've never had anybody saying continuing problems they've experienced at a new practice.' (Staff 8, pharmacyl

Patient participants also noted emotional attachment as a barrier to relocation:

I'd be very, very upset if / was asked to leave. (Patient 10, male, age 45 years, SHHC)

\section{Summary of key issues}

Box 2 summarises the facilitators and barriers to relocation and integration of patients from the SHHC to mainstream practices that were identified in this study.

\section{DISCUSSION}

\section{Summary}

This study has shown the key barriers and facilitators relating to the relocation process of patients from a SHHC to mainstream general practices. Barriers and facilitators were identified in relation to TDF domains and included: patients' intentions to relocate (suchas expression ofreluctance to relocate); environmental context and resources in relation to specialist and mainstream practices lincluding assessment of housing and clinical stability, and the difficulties encountered in establishing the former); beliefs about consequences regarding relocation to a mainstream practice Isuch as patients' apprehension about

\section{Box 2. Facilitators and barriers of relocation from a SHHC to a mainstream practice}

TDF domain

Beliefs about consequences

\begin{tabular}{l} 
Intentions \\
\hline Environmental context and resourc
\end{tabular}

\section{Sub-theme}

- Patient's beliefs about continuation of their ongoing healthcare needs on relocation

- Patient's ability to integrate

- Meeting new staff at mainstream practices

- Perceptions of mainstream practice

- Patient's intentions (or lack of) to relocate

- Lack of effective means to establish a patient's housing status

- The SHHC resources (or lack of) in communicating and assisting people to relocate once eligible

- Communication (or lack of) between SHHC and mainstream practice

- Diverse policies and operating rules in mainstream practices in registering a patient from a

SHHC, for example photographic ID requirements

- Patient's access (or lack of) to resources, for example, a telephone in maintaining communication during relocation

- Lack of continuation of services such as podiatry and dentistry at mainstream practices after relocation

\begin{tabular}{|c|c|c|c|}
\hline Knowledge & $\begin{array}{l}\text { - Patient's knowledge (or lack of) of relocation processes } \\
\text { - Lack of knowledge of rules and policies of mainstream practices } \\
\text { - Patient's knowledge (or lack of) about eligibility for relocation } \\
\text { - Knowledge and experience of SHHC staff in managing homeless and formerly homeless people } \\
\text { - Mainstream practice staff knowledge about relocation activity }\end{array}$ & $\begin{array}{c}2 \\
2 \\
2 \\
2 \\
2\end{array}$ & $\begin{array}{c}2 \\
2 \\
2 \\
2\end{array}$ \\
\hline Skills & $\begin{array}{l}\text { - Formerly homeless person's skills and abilities around integration } \\
\text { (adapting to the culture) in mainstream practices }\end{array}$ & 2 & 2 \\
\hline Social and professional role and identity & $\begin{array}{l}\text { - Patients not perceiving the SHHC as a SHHC for those experiencing homelessness } \\
\text { - Changing healthcare/lifestyle needs of patients serving as a prompt to relocation } \\
\text { - Ability of pharmacists to assist in the relocation process } \\
\text { - The role of staff at the SHHC in facilitating relocation }\end{array}$ & $\begin{array}{l}\checkmark \\
\checkmark \\
s\end{array}$ & $\checkmark$ \\
\hline Beliefs about capabilities & - Ability (or lack off) to integrate into mainstream practice & $\checkmark$ & $\checkmark$ \\
\hline Social influences & $\begin{array}{l}\text { - Experiences and influences of patients who had previously relocated } \\
\text { - Positive relationships with staff at a SHHC }\end{array}$ & $\checkmark$ & 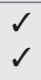 \\
\hline Reinforcement & $\begin{array}{l}\text { - Role of healthcare professionals, administrative staff, social care workers, } \\
\text { and family and friends in reinforcing and facilitating relocation }\end{array}$ & $\checkmark$ & \\
\hline Emotion & $\begin{array}{l}\text { - Emotional attachment to the SHHC } \\
\text { - Patient's expression of emotions in relation to relocating and integrating in mainstream practice }\end{array}$ & & 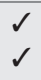 \\
\hline
\end{tabular}

SHHC $=$ specialist homeless healthcare centre. TDF $=$ Theoretical Domains Framework

Facilitator Barrier

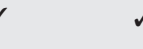

2

$\checkmark$

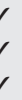

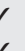

$\checkmark$

到

2
$\checkmark$
$\checkmark$

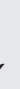


establishing new relationships with staff at mainstream practices); knowledge of relocation processes and mainstream practices (such as patients' lack of knowledge of the relocation processes); skills in relation to integration (such as skills around adapting to mainstream practices) social and professional role and identity of staff and patients (such as the role of staff in facilitating relocation); beliefs about capabilities in relation to ability to relocate and integrate (such as perceived ability to integrate at a mainstream practice) reinforcement of relocation (such as the role of others in reinforcing and facilitating relocation); social influences and the positive or negative effect on relocation (such as positive relationships established with staff at the SHHC serving as a barrier); and emotion attached to relocating lemotional attachment to the SHHC and the resultant negative impact on desire to relocate).

\section{Strengths and limitations}

This is the first study to explore perspectives of formerly homeless patients in relocating from a SHHC to a mainstream practice in the local area. The use of theory and steps taken to promote rigour and trustworthiness of the findings, particularly with regard to the expert review of study materials, added to the strength of the study. A further strength of the research was in terms of reflexivity; the research team was multidisciplinary and thus ensured that the study was conducted with a broad focus.

However, there are limitations hence the findings should be interpreted with caution. Because of the nature of recruitment and identification of potential eligible participants, it may be that those recruited did not represent a broad demographic. Response bias may also have been a factor in the research, in that participants may have responded with socially desirable answers. Further, the number of patients who had moved from the SHHC to mainstream practices was small as a result of challenges in identifying and recruiting the target population. Lastly, there are potential limitations with regard to the transferability of findings since the key outcomes may be specific to the particular context, population, and environment in which they were studied and therefore may not be easily transferred to other locations.

\section{Comparison with existing literature}

Participants in this study reported that formerly homeless patients often faced difficulty in relocating to a mainstream practice if they were not in possession of photographic identification. Previous studies have paid attention to the fact that homeless patients often experience issues with registering at mainstream general practices because of a lack of fixed abode, ${ }^{11}$ and identification documents. ${ }^{12}$ This study has identified that even once settled at a permanent address, formerly homeless patients may still find it challenging to register at a mainstream general practice.

A previous report suggested that patients in a homeless healthcare centre appreciate the specialist nature of the services offered. ${ }^{26}$ The current study has added to our knowledge that such high levels of satisfaction with SHHC services, as well as perceived lack of tailored services at mainstream practices, are associated with patients' reluctance to relocate. With approximately $50 \%$ of the patients being prescribed repeat methadone through the SHHC involved in this study, lack of such substance misuse service provision at mainstream practices may also have posed a barrier to some patients' intentions to relocate.

This study also provides patient perspectives on the role of SHHC staff as well as healthcare and social care workers who dedicated time specifically to facilitating relocation. The results reflect the recommendation that specialist practices may benefit from having a 'GP liaison or resettlement worker'. ${ }^{20}$ This study indicates that substance use workers are ideally suited to undertake such liaison work, not just for housing resettlement but also for enabling the relocation from $\mathrm{SHHC}$ to mainstream general practices in their resettled localities.

A potential barrier to relocation may be fear of stigmatisation or discrimination at mainstream practices. These findings corroborate the existing literature, which suggests that poor prior experiences with healthcare professionals and negative attitudes from staff may serve as barriers to use of a mainstream practice..$^{10,27}$ This study has identified that in addition to personal experiences, the perspectives of those who have previously relocated also strongly influence their peers who are waiting to relocate.

The findings from this study further emphasised the complexity of the relocation process in terms of barriers and facilitators. Barriers and facilitators of relocation often varied between individuals. These findings suggest that any approach to changing behaviour in a population should be tailored in accordance with the individual. This reflects guidance issued by the National 
Institute for Health and Care Excellence on promoting behaviour change, which advises that behaviour change programmes and interventions are tailored to individual needs. ${ }^{28}$

\section{Implications for research and practice}

This study has outlined the complexity of the processes involved in identifying and enabling formerly homeless patients to relocate to mainstream practices. The relocation process is both time and resource intensive with input required from patients, healthcare, administrative and social care staff at both practices. Accordingly, exploration of the key barriers and facilitators in accordance with TDF domains has resulted in identification of the following recommendations, which may be beneficial in supporting patients during relocation:

- increasing patients' knowledge of eligibility for relocation and mainstream practices' policies and regulations;

- peer support networks;

- provision of reassurance with respect to continuation of health care and with regard to integrating and developing relationships at mainstream practices;

- provision of information sources, such as the 'My right to access health care' cards, which outline guidance for patients on registering at mainstream practices; ${ }^{13}$

- greater involvement of community pharmacists in relocation processes; and

- development of individualised plans to promote behaviour change. This may involve mapping of TDF domains to behaviour change techniques, which are typically incorporated into intervention design for behaviour change programmes as a means to facilitate change. ${ }^{29}$

Further, staff at specialist and general practices supporting relocation may benefit from the following recommendations:

- provision of information regarding relocation processes;

- support of newly-relocated people via proactive signposting to where additional healthcare services may be accessed;

- support of a professional who is dedicated to facilitating relocation; and

- sharing of specialist knowledge and skills, between staff at both practices, in managing patients experiencing homelessness.

Understanding the perspectives of those mainstream general practices that have been reluctant to register formerly homeless patients from SHHCs would also enable further insight into the barriers and facilitators to the relocation process.

\section{Funding}

This study was funded by the Health Improvement Fund, NHS Grampian, 2015.

\section{Ethical approval}

This study was given NHS East Midlands approval (REC 2 15/EM/0535) and NHS Grampian Research and Development approval Ref 2015RG007.

\section{Provenance}

Freely submitted; externally peer reviewed.

\section{Competing interests}

The authors have declared no competing interests.

\section{Acknowledgements}

Thanks to NHS Grampian, the general practices and community pharmacies that were involved in the research, study participants, Caroline McNiff for her part in data collection, and Jeanette Lowe for transcription of audiorecordings.

\section{Discuss this article}

Contribute and read comments about this article: bjgp.org/letters 


\section{REFERENCES}

1. Crisis. About homelessness. https://www.crisis.org.uk/ending-homelessness/ about-homelessness/ laccessed 19 Dec 2017).

2. Fitzpatrick S, Pawson H, Bramley G, et al. The homelessness monitor: Great Britain 2016. 2016. https://www.crisis.org.uk/media/237496/the_homelessness_ monitor_great_britain_2016.pdf (accessed 19 Dec 2017).

3. Shelter (England). Life on the margins: over a quarter of a million without a home in England today. 2016. https://england.shelter.org.uk/media/ press_releases/articles/life_on_the_margins_over_a_quarter_of_a_million without_a_home_in_england_today (accessed 19 Dec 2017).

4. National Audit Office. Department for Communities and Local Government. Homelessness. https://www.nao.org.uk/wp-content/uploads/2017/09/ Homelessness.pdf laccessed 5 Jan 2018).

5. Shelter (Scotland). Housing and homelessness statistics. 2017. http://scotland shelter.org.uk/housing_policy/key_statistics/homelessness_facts_and_research laccessed 19 Dec 2017).

6. Gadermann AM, Hubley AM, Russell LB, Palepu A. Subjective health-related quality of life in homeless and vulnerably housed individuals and its relationship with self-reported physical and mental health status. Soc Indic Res 2014; 116(2): $341-352$

7. Wright NM, Tompkins CN. How can health services effectively meet the health needs of homeless people? Br J Gen Pract 2006; 56(525): 286-293.

8. Crisis. Drugs and alcohol. https://uww.crisis.org.uk/ending-homelessness/ health-and-wellbeing/drugs-and-alcohol/ laccessed 19 Dec 2017).

9. Hwang SW, Tolomiczenko G, Kouyoumdjian FG, Garner RE. Interventions to improve the health of the homeless: a systematic review. Am J Prev Med 2005 29(4): $311 . e 75$

10. Crisis. Policy brief: Critical condition: vulnerable single homeless people and access to GPs. 2002. http.//opinion-former-resources.politics.co.uk/ microsites2/364304/graphics/gppolicybrief.pdf (accessed 5 Jan 2018).

11. Deloitte Centre for Health Solutions. Healthcare for the homeless: homelessness is bad for your health. 2012. https://www2.deloitte.com/uk/en/ pages/life-sciences-and-healthcare/articles/healthcare-for-the-homeless.html laccessed 19 Dec 2017).

12. NHS. Healthy London Partnership. Helping people who are homeless access GP practices. 2017. https://www.healthylondon.org/hlp-archive/homeless/ healthcare-cards.html (accessed 5 Jan 2018).

13. Gill P, MacLeod U, Lester H, Hegenbarth A. Improving access to health care for gypsies and travellers, homeless people and sex workers. An evidencebased commissioning guide for Clinical Commissioning Groups and Health \& Wellbeing Boards. London: Royal College of General Practitioners, 2013.

14. Dixon Woods M, Kirk D, Agarwal S, et al. Vulnerable groups and access to health care: a critical interpretive review. Report for the National Co-ordinating Centre for NHS Service Delivery and Organisation R\&D (NCCSDO). 2005. http://www. netscc.ac.uk/hsdr/files/project/SDO_FR_08-1210-025_V01.pdf laccessed 19 Dec 2017).

15. Office of the Chief Analyst, Department of Health. Healthcare for single homeless people. Department of Health, 2010. https://uww.housinglin.org.uk/
assets/Resources/Housing/Support_materials/Other_reports_and_guidance/ Healthcare for_single_homeless_people.pdf laccessed 19 Dec 2017).

16. Report of an Independent Commission for the Royal College of General Practitioners and the Health Foundation. Guiding patients through complexity: modern medical generalism. 2011. http://www.health.org.uk/sites/health/files/ GuidingPatientsThroughComplexityModernMedicalGeneralism.pdf laccessed 19 Dec 2017).

17. Aspinall P. Inclusion Health. Inclusive practice. Vulnerable migrants, gypsies and travellers, people who are homeless, and sex workers: a review and synthesis of interventions/service models that improve access to primary care \& reduce risk of avoidable admission to hospital. 2014. https://www.gov.uk/ government/uploads/system/uploads/attachment data/file/305912/Inclusive Practice.pdf (accessed 5 Jan 2018).

18. Mehet D, Ollason M. Health services for homeless people in London: case for action. NHS London, 2015. http://www.londonscn.nhs.uk/wp-content/ uploads/2015/03/mh-sclg-homeless-19062015.pdf (accessed 19 Dec 2017).

19. Lester H, Wright N, Heath I; RGCP Health Inequalities Standing Group. Developments in the provision of primary health care for homeless people. $\mathrm{Br} \mathrm{J}$ Gen Pract 2002; 52(475): 91-92.

20. Wright NM, Tompkins CN, Oldham NS, Kay DJ. Homelessness and health: what can be done in general practice? J R Soc Med 2004; 97(4): 170-173.

21. Cane J, O'Connor D, Michie S. Validation of the theoretical domains framework for use in behaviour change and implementation research. Implement Sci 2012; 7: 37

22. NHS Grampian. Annual report 2006/07: The annual review of the performance of NHS Grampian. NHS Grampian, 2007. http://foi.nhsgrampian.org/globalassets/ foidocument/foi-public-documents1---all-documents/annualreportpdf.pdf laccessed 19 Dec 2017)

23. Ritchie J, Lewis J, Nicholls CM, Ormston R. Qualitative research practice: a guide for social science students and researchers. London: Sage, 2014.

24. Gale NK, Heath G, Cameron E, et al. Using the framework method for the analysis of qualitative data in multi-disciplinary health research. BMC Med Res Methodol 2013; 13(1): 117

25. Bryman A. Social research methods. 4th edn. Oxford: Oxford University Press, 2012

26. Hewett NC. How to provide for the primary health care needs of homeless people: what do homeless people in Leicester think? Br J Gen Pract 1999. 49(447): 819 .

27. Love JG, Love AP, Vertigans S, Sutton PW. Health \& homelessness in Aberdeen City: a report for the Scottish Health Council. Open Access Institutional Repository at Robert Gordon University 2007. https://openair.rgu.ac.uk/ handle/10059/174 laccessed 5 Jan 2018).

28. National Institute for Health and Care Excellence. Behaviour change: individual approaches. Public health guideline [PH49]. 2014. https://www.nice.org.uk/ Guidance/PH49 laccessed 19 Dec 2017).

29. Michie S, Wood CE, Johnston M, et al. Behaviour change techniques: the development and evaluation of a taxonomic method for reporting and describing behaviour change interventions la suite of five studies involving consensus methods, randomised controlled trials and analysis of qualitative data). Health Technol Assess 2015; 19(99): 1-188. 